\title{
Linfoma não Hodgkin gástrico
}

Gastric non-Hodgkin Lymphoma

\author{
Renata O. Costa \\ Abrahão E. Hallack Neto ${ }^{2}$ \\ Dalton A. F. Chamone \\ Vera Lúcia Aldred ${ }^{4}$ \\ Luis F. Pracchia \\ Juliana Pereira ${ }^{6}$
}

\begin{abstract}
Os linfomas extralinfonodais representam aproximadamente 1/3 de todos os linfomas não Hodgkin (LNH) e, embora possam ter início em qualquer tecido, mais frequentemente acometem o trato gastrointestinal, sendo o estômago o órgão responsável pela grande maioria dos casos. Os linfomas primários gástricos são comumente LNH, sendo representados em mais de $95 \%$ dos casos pelo linfoma difuso de grandes células B e pelo linfoma MALT (mucosa associated lymphoid tissue). De evolução indolente, o linfoma MALT destaca-se por ser um modelo de câncer secundário à estimulação antigênica crônica exercida por uma bactéria denominada Helicobacter pylori (HP). No outro polo, situa-se o linfoma difuso de células $B$ (LDGCB), que, de patogênese duvidosa, pode tratar-se de uma transformação de LNH MALT ou ainda se caracterizar por um linfoma "de novo". Neste estudo, revisamos a literatura, enfatizando aspectos importantes à prática clínica destes linfomas. Rev. Bras. Hematol. Hemoter.
\end{abstract}

Palavras-chave: Linfoma;Linfoma não Hodgkin; neoplasias gástricas.

\section{Introdução}

Os linfomas não Hodgkin compreendem um grupo heterogêneo de neoplasias malignas linfocitárias cuja incidência vem aumentando nas últimas décadas. Estimativas americanas apontam para aproximadamente 66 mil novos casos e 19 mil mortes pela doença em 2008. ${ }^{1}$ Neste espectro diverso de doença, o envolvimento extralinfonodal é bastante frequente e corresponde a $40 \%$ dos casos, sendo o trato gastrointestinal (TGI) o local mais comum, seguido da pele e sistema nervoso central (SNC). ${ }^{2}$ No TGI, o estômago é o órgão mais acometido, responsável por $60 \%$ dos casos.

Os linfomas gástricos têm uma distribuição mundial, com áreas de maior incidência possivelmente relacionadas a altas taxas de infecção por Helicobacter pylori (HP), como no norte da Itália, tendo sido esta uma das primeiras evidências epidemiológicas de causalidade na etiopatogênese deste linfoma. $^{3}$

\section{Conceito e linfomagênese do linfoma MALT gástrico}

Foi no início dos anos 80 que Isaacson e Wright sugeriram o termo linfoma MALT a partir de observações de semelhanças histológicas e imuno-histoquímicas entre o linfoma do mediterrâneo e o envolvimento primário do estômago por linfoma, sugerindo na ocasião uma histogênese distinta da dos linfomas linfonodais. ${ }^{4}$

Posteriormente, esse conceito de linfoma MALT incluiu também casos de linfoma de outros sítios extralinfonodais,

${ }_{2}^{1}$ Médica hematologista. Médica assistente do HC-FMUSP. Professora da UniLuz.

${ }_{3}^{2}$ Médico hematologista. Professor da Universidade Federal de Juiz de Fora - MG.

${ }_{4}^{3}$ Livre Docente. Professor Titular de Hematologia Universidade de São Paulo (USP) - SP.

${ }^{4}$ Médica patologista.

${ }^{5}$ Médico hematologista. Médico Assistente do HC-FMUSP - SP.

${ }^{6}$ Médica hematologista. Professora da Universidade de São Paulo (USP) - SP.

Hospital das Clínicas da Universidade de São Paulo

Correspondência: Abrahão E. Hallack Neto

Rua Dr. José de Alencar Medeiros, 115 - Graminha

36.001-970 - Juiz de Fora-MG - Brasil

Fone (32) 3215-1523 Fone

E-mail:abrahallack@uol.com.br 
como glândula salivar, tireoide e pulmão, e, desde então, o termo linfoma MALT tem sido amplamente utilizado para caracterizar este tipo de linfoma. Os linfomas MALT foram reconhecidos como entidade própria na classificação Real (Revised European-American Classification of Lymphoid Neoplasms) e atualmente na classificação da Organização Mundial de Saúde (OMS) como linfoma da zona marginal extralinfonodal do tecido linfoide associado a mucosa.,

Como não existe tecido linfoide no estômago normal, a associação entre o MALT gástrico e HP foi verificada há quase vinte anos atrás, a partir da constatação de que a infecção crônica por esta bactéria estaria relacionada com aparecimento de MALT adquirido no estômago. ${ }^{7}$ Em estudo retrospectivo, Wotherspoon e colaboradores identificaram, em 110 pacientes acometidos por linfoma MALT gástrico, a presença de HP em $92 \%$ dos casos. ${ }^{8}$

Em São Paulo, em estudo retrospectivo com 22 casos de linfoma gástrico submetidos a revisão histológica e pesquisa de HP, 13 foram classificados como linfoma MALT, e pôde-se identificar a presença da bactéria em 92,3\% dos casos. ${ }^{9}$ Evidências mais diretas de HP na patogênese do linfoma gástrico foram confirmadas por ensaios clínicos e de biologia celular, onde amostras de células B obtidas após ressecção de LNH MALT gástrico proliferaram e aumentaram a expressão de interleucina-2 e de imunoglobulina tumoral específica quando submetidas à cultura com HP. ${ }^{10}$

Com grande parte da população mundial infectada pela bactéria e apenas uma pequena parte desenvolvendo linfoma MALT, um dos desafios atuais é o de tentar estabelecer os fatores relacionados à bactéria ou ao hospedeiro, que estariam associados ao desenvolvimento dessa doença. De patogênese controversa, o citotoxin-associated gen A (CagA), à semelhança do observado no adenocarcinoma gástrico, pode ter um papel no desenvolvimento do linfoma MALT por causar intensa resposta inflamatória, produção de citocinas, ativação de neutrófilos e dano ao ácido desoxirribonucleico (DNA), com instabilidade cromossômica facilitando o aparecimento de translocações, como a $\mathrm{t}(11 ; 18) .{ }^{11,12}$

Embora a grande maioria das infecções gástricas sejam causadas pela HP, pequena porcentagem dos casos tem sido atribuída à infecção por $H$. heilmannii, bactéria comumente encontrada em animais. Apesar de causar gastrite menos intensa do que a HP, um estudo com 202 indivíduos infectados por $H$. heilmannii constatou maior incidência de linfoma MALT entre indivíduos infectados pelo $H$. heilmannii do que pela HP. ${ }^{13}$ Modelos animais demonstraram desenvolvimento de linfoma MALT histológico (lesão linfoepitelial) e clinicamente semelhante ao observado nos seres humanos, demonstrando ser possível que a infecção por $H$. heilmannii também seja uma causa de linfoma MALT. ${ }^{14}$

\section{Patologia molecular do linfoma MALT gástrico}

Três translocações diferentes (Figura 1) foram descritas no linfoma MALT gástrico e, embora envolvam diferentes genes, parecem terminar em uma via comum de ativação do fator de transcrição nuclear (NFKB), contribuindo para o desenvolvimento tumoral por ativação celular, proliferação e inibição de apoptose. ${ }^{15}$

A translocação $(11 ; 18)(q 21: q 21)$ é encontrada em aproximadamente $30 \%$ a $50 \%$ dos casos de linfoma MALT, ocorrendo uma fusão do gene inibidor de apoptose API2, localizado no cromossomo 11 e do gene MLT, localizado no cromossomo 18 , que resulta na inibição das proteínas próapoptóticas caspases 3, 7 e 9 e ativação do fator oncogênico nuclear KB (NF-KB). Essa anormalidade foi descrita até o momento apenas no LNH MALT, não sendo encontrada no linfoma da zona marginal esplênica ou nodal ou no linfoma de alto grau do estômago. ${ }^{16,17}$ Embora comum, a frequência com que a $\mathrm{t}(11 ; 18)$ é encontrada no linfoma MALT é bastante variável, podendo ser detectada em 30\% a 40\% dos LNH MALT de estômago e de pulmão, respectivamente. E mesmo sendo mais comumente observada em casos de linfoma com disseminação local e sistêmica, e nos casos resistentes à erradicação da HP, raramente é encontrada no linfoma MALT transformado para alto grau. ${ }^{18-22}$

A $t(1 ; 14)$ também pode ser encontrada no linfoma MALT, porém, em menor frequência, conferindo ao tumor maior crescimento autônomo, em consequência da hiperexpressão de uma forma mutada do gene bcl-10. A t(14;18), 
descrita em torno de $20 \%$ dos casos, é rara nos linfomas gástricos, acometendo mais frequentemente os linfomas MALT da glândula salivar e lacrimal. ${ }^{23,24,25}$

O desenvolvimento do linfoma MALT gástrico também pode ser influenciado por alterações no gene p53; a inativação parcial desse gene parece estar relacionada ao desenvolvimento do linfoma MALT e sua inativação completa com a transformação para linfoma gástrico de alto grau histológico. ${ }^{26}$

\section{Histologia e imuno-histoquímica}

Na histologia, observamos células de tamanho pequeno a médio, semelhantes a centrócitos. As células neoplásicas podem apresentar características monocitoides ou linfoplasmocíticas, podendo haver predomínio de qualquer desses achados ou a coexistência de ambas no mesmo tumor. Podem ser encontradas algumas células grandes, embora tipicamente encontremos a lesão linfoepitelial que se caracteriza pela invasão das glândulas gástricas por agregados de células tumorais (Figura 2). No linfoma difuso de grandes células B (LDGCB) gástrico, lesões linfoepiteliais são raramente encontradas, mais frequentemente observam-se linfócitos grandes, como centroblastos, imunoblastos e plasmablastos. $^{27}$

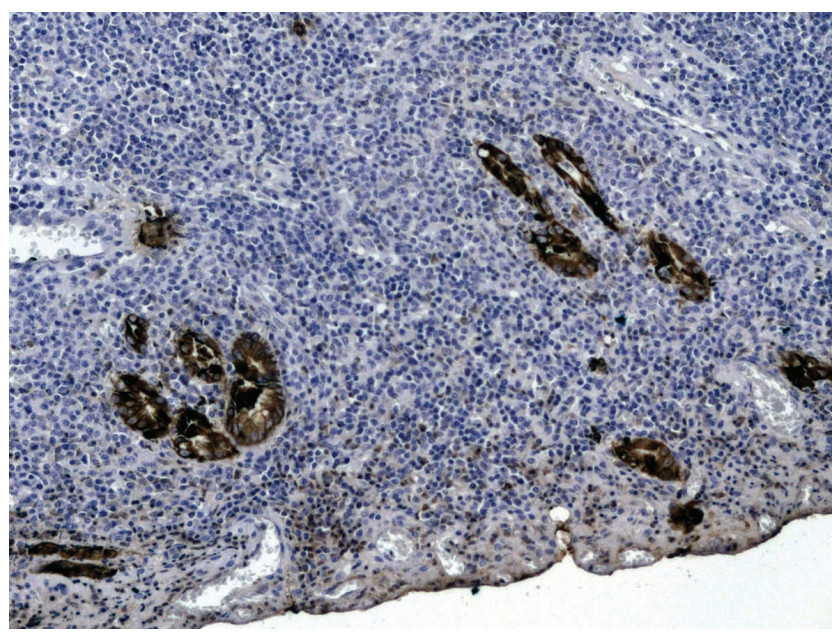

Figura 2. Anatomopatológico de linfoma MALT gastrico

A definição histológica na biópsia gástrica pode ser difícil, pois não é raro o achado concomitante de áreas de grandes células no linfoma MALT e pequenas células em casos de linfoma de alto grau, sugerindo transformação de um linfoma de baixo grau para alto grau. Em estudo realizado com dez amostras de gastrectomia, em que havia a coexistência de ambos os componentes histológicos, pôde-se demonstrar a expressão da mesma imunoglobulina (Ig) de superfície após análise imuno-histoquímica, confirmando a transformação de linfoma de baixo grau para alto grau, sendo, recente- mente, relatada a relação clonal entre pequenas e grandes células no linfoma MALT gástrico. ${ }^{28,29}$

Embora tenha sido proposta uma estratificação histológica para esses tumores, em que a presença de um componente de grandes células em um linfoma MALT de baixo grau resultava em piora na sobrevida global, a separação histológica não é adotada atualmente na prática clínica devido à sua baixa reprodutibilidade. ${ }^{30}$

O linfoma MALT gástrico apresenta imunofenotipagem típica de células da Zona Marginal, expressa antígenos panB (CD20, CD79a, e marcadores de células B maduras (CD21 e CD35), podendo ser bcl-2+ e CD43+, não expressando geralmente os antígenos CD5, CD23 e ciclina D1. Suas células expressam Ig de superfície, menos frequentemente Ig citoplasmática, mais comumente IgM, com restrição para cadeia leve. $O$ índice de proliferação é pequeno, com baixa expressão de Ki67 (Figura 3), diferente dos LDGCB, em que encontramos uma alta expressão de Ki67 (Figura 4). Na maioria dos casos

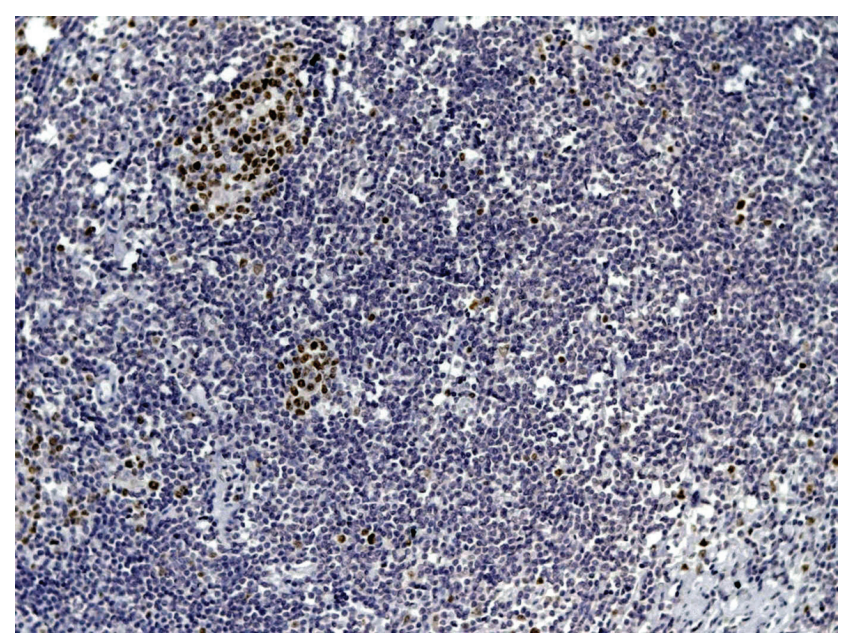

Figura 3. MALT com baixa expressão do marcador Ki67

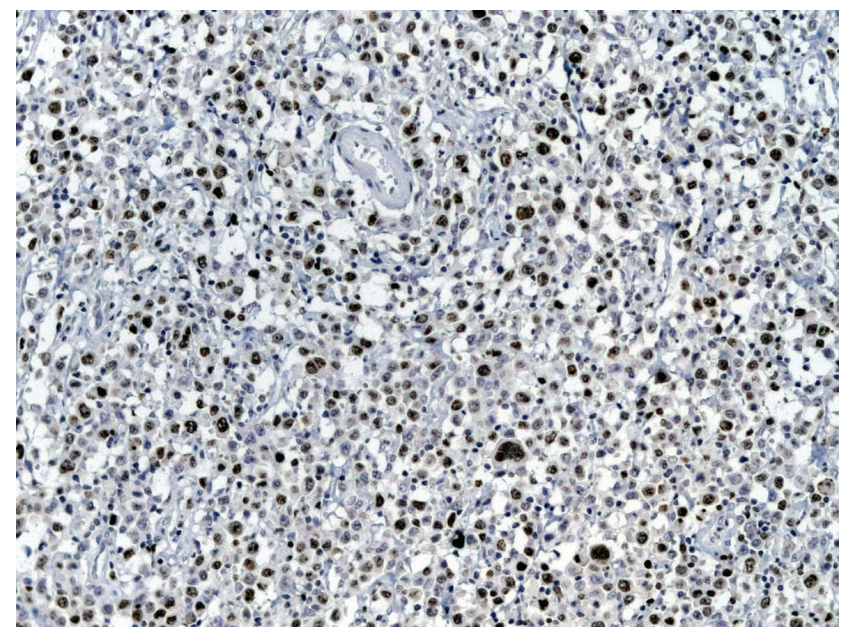

Figura 4. LDGCB com alta expressão do marcador Ki67 
de MALT gástrico, existe um número significativo de linfócitos T CD4+, corroborando a hipótese de que as células T não tumorais promovem o crescimento das células B. ${ }^{31}$

\section{Manifestações clínicas e abordagem diagnóstica}

\section{Manifestações clínicas}

O linfoma gástrico é clinicamente distinto dos linfomas nodais, a idade média ao diagnóstico é de 60 anos e há um discreto predomínio para o sexo masculino. A maior parte dos pacientes apresenta-se com queixas dispépticas inespecíficas, sendo a dor epigástrica o achado principal e ocorrendo em mais de $70 \%$ dos casos, podendo ocorrer inapetência, náuseas, vômitos, hematêmese e melena em menos da metade dos casos..$^{32,33,34}$ Os sintomas B, a elevação do nível de desidrogenase láctica (DHL) e o aumento de $\beta_{2}$ microglobulina $\left(\beta_{2} \mathrm{M}\right)$ ocorrem em menos de $10 \%$ dos LNH gástricos, sendo que, no LDGCB, podem estar presentes em até $30 \%$ dos casos. ${ }^{35,36}$

Em comparação ao linfoma nodal indolente, que, ao diagnóstico, frequentemente acomete diversas cadeias ganglionares e medula óssea, o linfoma de estômago tem tendência a permanecer localizado por longo tempo, podendo apresentar-se de forma disseminada em até um terço dos pacientes ao diagnóstico. ${ }^{37}$ Quando disseminam, as células tumorais tendem a ocupar a zona marginal dos linfonodos e menos frequentemente infiltram a zona marginal esplênica e a mucosa intestinal. ${ }^{38,39}$

\section{Diagnóstico e diagnóstico diferencial}

$\mathrm{Na}$ endoscopia, observam-se mais frequentemente lesões ulceradas, gastrite eritematosa, erosões e pólipos, sendo o antro gástrico a região mais envolvida. $\mathrm{O}$ acometimento do estômago pode ser multifocal, sendo a presença de grandes massas tumorais rara e, quando presentes, mais comumente representam casos de linfoma de alto grau. Como não existe um padrão endoscópico típico de acometimento por LNH gástrico, o diagnóstico inicial pode variar de gastrite a carcinoma, porém não é raro que o linfoma indolente tenha um aspecto endoscópico de lesão ulcerosa benigna e que o linfoma de alto grau tenha um aspecto "maligno", tipo carcinomatoso..$^{35}$

Os principais diagnósticos diferenciais são outros linfomas B de células pequenas, principalmente os linfomas da zona do manto (LZM) e o linfoma folicular (LF) e, embora a histologia seja semelhante, a imuno-histoquímica com expressão de CD5 e de ciclina D1 é característica dos LZM, e a presença do antígeno CD10 está associada ao LF, que pode apresentar lesão linfoepitelial típica do linfoma MALT. $^{40}$

Além disso, métodos de imunofenotipagem e/ou moleculares para detecção de monoclonalidade são recomendados em casos duvidosos, embora a histologia ainda seja o padrão-ouro no diagnóstico dos linfomas gástricos. ${ }^{6,41,42}$

\section{Tratamento}

Existem duas situações em que o tratamento do linfoma MALT parece estar bem estabelecido; nos pacientes com doença localizada e comprometimento superficial da mucosa gástrica, a erradicação da HP parece ser a melhor opção, e, em um extremo oposto, encontram-se aqueles com doença avançada, que devem ser tratados de forma semelhante a outros linfomas nodais indolentes.

\section{Erradicação da $H P$}

O primeiro relato de regressão do LNH gástrico após terapia de erradicação de HP data de 1993; nesta mesma época, o grupo alemão de estudo de linfoma MALT demonstrou uma taxa de remissão completa (RC) de $70 \%$ em 33 pacientes tratados com antibióticos. ${ }^{43}$

Estudo prospectivo com 34 portadores de LNH MALT submetidos à erradicação da bactéria demonstrou RC em $41 \%$ (14) dos pacientes; porém, apenas 28 pacientes tinham infecção por HP documentada e, desses, 14 (50\%) responderam ao esquema de erradicação da bactéria; já os pacientes que não apresentavam HP e que foram tratados com antibioticoterapia não obtiveram resposta à terapêutica antimicrobiana implementada em $100 \%$ dos casos. ${ }^{44}$

Diversos grupos vêm reproduzindo estes resultados, com taxas de RC que variam de $50 \%$ a $80 \%$. Um estudo prospectivo com 95 portadores de linfoma MALT gástrico demonstrou $62 \%$ de RC nos tratados com antibioticoterapia para $\mathrm{HP},{ }^{45}$ sendo a resposta ao tratamento antibiótico de erradicação para HP influenciada pela presença de doença localmente avançada (infiltração de camadas mais profundas do estômago), em grandes tumores com massas tipo bulky e em casos de linfoma com aumento em áreas de grandes células. ${ }^{46}$

Embora a relevância clínica do grau histológico tenha sido demonstrada em trabalhos separando os pacientes em quatro grupos distintos de acordo com os achados histológicos, nos quais a presença de áreas de grandes células em linfoma MALT teve impacto negativo na sobrevida global (SG), comparando-se aos casos sem essas áreas, a pouca reprodutibilidade desses critérios morfológicos os torna de valor questionável. ${ }^{30,47}$

Apesar disso, além de relatos anedóticos demonstrando RC em LDGCB tratados com erradicação da HP, em um estudo publicado por Nakumura e cols, em pacientes com histologia gástrica com ou sem áreas de grandes células, que foram tratados com erradicação do HP, a única variável prognóstica para resposta do linfoma ao uso de antibióticos foi o padrão de invasão da parede do estômago avaliada por ultrassonografia endoscópica. ${ }^{48,49,50}$

O grupo francês de estudo de linfomas digestivos demonstrou, em estudo multicêntrico com 44 pacientes selecionados para tratamento com antibiótico, que a maior taxa de resposta (78\%) foi obtida nos casos com acometimento ape- 
nas da mucosa. Quando houve comprometimento de submucosa, muscular própria e serosa, a taxa de resposta foi de $43 \%, 20 \%$ e $25 \%$ respectivamente, sem resposta ao tratamento à erradicação bacteriana nos pacientes com adenomegalia perigástrica. $^{51}$

A presença da $\mathrm{t}(11 ; 18)$ interfere na resposta à erradicação de HP demonstrando tratar-se de um fator de mau prognóstico, mesmo em pacientes com estádios precoces ao diagnóstico. Em pacientes com linfoma gástrico localizado não respondedores ao tratamento antibiótico, detectou-se o gene híbrido API2-MLT em 75\% dos casos, sem que tivesse sido encontrado nos pacientes respondedores. $^{20}$

\section{Quimioterapia}

Embora aproximadamente $30 \%$ dos pacientes com LDGCB se apresentem com estádios precoces ao diagnóstico, eles devem sempre ser tratados com esquema poliquimioterápico, já que, com radioterapia isolada, a recidiva sistêmica é $20 \%$ superior à combinação de quimioterapia e radioterapia, com SLD inferior a $50 \% .^{52}$

Para a maioria dos pacientes com LDGCB que se apresenta com estádio avançado ao diagnóstico, embora adotado há mais de 20 anos, o clássico esquema CHOP deve ser utilizado, visto que, mesmo quando comparado a esquemas de $3^{\text {a }}$ geração, demonstrou superioridade em termos de custo e toxicidade, sem diferença estatisticamente significativa quanto a RC, SLD e SG. ${ }^{53,54}$ Atualmente, a associação do anticorpo monoclonal anti-CD20 ao esquema quimioterápico demonstrou aumento na SG dos pacientes com LDGCB. ${ }^{55}$

Estudo recente com o objetivo de avaliar se a associação de quimioterapia adjuvante com clorambucil após erradicação da HP traria benefício após atingirem RC, randomizou os pacientes com LNH MALT para receberem clorambucil $6 \mathrm{mg} / \mathrm{m}^{2} / \mathrm{d}$ por 14 dias, por seis meses, ou por serem observados, sem benefícios para o grupo submetido a quimioterapia de "consolidação", embora para os não respondedores ao esquema de erradicação, $58 \%$ atingiram RC com o esquema monoquimioterápico. ${ }^{56}$

Em estudo fase II, a eficácia do análogo de purina cladribina na dose de $0,12 \mathrm{mg} / \mathrm{kg} / \mathrm{d}$ por cinco dias, por no máximo seis ciclos, foi testada em 25 pacientes, 19 portadores de LNH gástrico. Todos os pacientes responderam ao esquema, com 21 (84\%) entrando em RC e quatro (16\%) em RP. A taxa de RC para linfoma MALT gástrico foi de $100 \%$ versus $43 \%$ para outros LNH MALT extragástricos. ${ }^{57} \mathrm{O}$ rituximabe foi testado em 34 pacientes com LNH MALT na dose de $375 \mathrm{mg} / \mathrm{m}^{2}$ por quatro semanas, 14 com linfoma gástrico; desses, quatro (29\%) obtiveram RC. ${ }^{58}$

\section{Tratamento cirúrgico e radioterápico}

Em estudo retrospectivo comparando pacientes submetidos apenas a tratamento cirúrgico ou cirurgia combinada com outras terapêuticas (quimioterapia e radioterapia) não houve diferença estatisticamente significativa entre os grupos. ${ }^{33}$ Outro estudo prospectivo de 208 pacientes submetidos à cirurgia ou tratamento conservador não demonstrou superioridade nos resultados de pacientes tratados cirurgicamente. ${ }^{59}$

Em estudo prospectivo com 17 pacientes com linfoma gástrico MALT estádios I e II, sendo cinco pacientes com infecção prévia por HP com falha ao tratamento antibiótico, tratados com RXT exclusiva, a taxa de sobrevida livre de evento (SLE) foi de $100 \%$ após seguimento de 27 meses, com leves toxicidades agudas (náuseas e refluxo). ${ }^{60}$

\section{Seguimento}

Não existem diretrizes para o seguimento de pacientes com linfoma gástrico; em nosso serviço realizamos EDA com pesquisa de HP e biópsia de áreas suspeitas a cada três meses no primeiro ano de seguimento, a cada seis meses no segundo ano e a seguir anualmente, considerando como refratários os pacientes com persistência histológica do linfoma MALT 12 meses após a erradicação do HP. ${ }^{61}$

\begin{abstract}
Extranodal lymphomas account for about $30 \%$ of all non-Hodgkin lymphomas (NHL), and although they can originate in any tissue, the gastrointestinal tract is the most commonly affected structure with the stomach being the most common subtype. Diffuse Large B cell lymphoma (DLBCL) and MALT (mucosa associated lymphoid tissue) lymphoma account for more than $95 \%$ of the cases of gastric lymphoma. The indolent development of MALT lymphoma stands out as it is a type of cancer subject to chronic antigen stimulation by the Helicobacter pylori bacteria. Conversely, diffuse large B cell lymphomas, whose pathogenesis is uncertain, can be a transformation from MALT NHL or perhaps a new type of lymphoma. In this study we carried out a review of the literature, stressing the key aspects of these lymphomas in the clinical practice. Rev. Bras. Hematol. Hemoter.
\end{abstract}

Key Words: Lymphoma; non-Hodgkin; stomach neoplasias.

\section{Referências Bibliográficas}

1. National Cancer Institute. Disponível em: htpp://www.cancer.gov

2. Zucca E, Roggero E, Bertoni F, Cavalli F. Primary extranodal nonHodgkin's lymphomas. Part 1: Gastrointestinal, cutaneous and genitourinary lymphomas. Ann Oncol. 1997;8(8):727-37.

3. Doglioni C, Wotherspoon AC, Moschini A, De Boni M, Isaacson PG. High incidence of primary gastric lymphoma in northeastern Italy. Lancet. 1992;339(8797):834-5.

4. Isaacson PG, Wright DH. Malignant lymphoma of mucosa-associated lymphoid tissue. A distinctive type of B-cell lymphoma. Cancer. 1983;52(8):1410-16.

5. Harris NL, Jaffe ES, Stein H, Banks PM, Chan JK, Cleary ML, et al. A revised European-American classification of lymphoid neoplasms: a proposal from the International Lymphoma Study Group. Blood. 1994;84(5):1361-92. 
6. Jaffe ES, Harris NL, Stein H, Vardiman JW. Pathology \& Genetics: Tumours of Haematopoietic and Limphoid Tissues. World Health Organization Classification of Tumours. Internacional Agency for Research on Cancer (IARC Press). Lyon 2001.

7. Stolte M, Eidt S. Lymphoid follicles in the antral mucosa: immune response to Campylobacter pylori? J Clin Pathol. 1989;42(12): 1269-71.

8. Wotherspoon AC, Ortiz-Hidalgo C, Falzon MR, Isaacson PG. Helicobacter pylori-associated gastritis and primary B-cell gastric lymphoma. Lancet. 1991;338(8776):1175-6.

9. Hungria VTM, Castro NS, Chiattone, CS, Paes, RPP. Helicobacter pylori associado a linfoma gástrico primário tipo MALT. Bol Soc Bras Hematol Hemoter. 1994;16:279-81.

10. Hussel T, Isaacson PG, Crabtree JE, Spencer J. The response of cells from-low grade B-cell gastric lymphomas of mucosa-associated lymphoid tissue to Helicobacter pylori. Lancet. 1993;342(8871): $571-4$

11. Eck M, Schmausser B, Haas R, Greiner A, Czub S, MüllerHermelink HK. MALT-type lymphoma of the stomach is associated with Helicobacter pylori strains expressing the CagA protein. Gastroenterology. 1997:112(5):1482-86.

12. Ye H, Liu H, Attygalle A, Wotherspoon AC, Nicholson AG, Charlotte $\mathrm{F}$, et al. Variable frequencies of $\mathrm{t}(11 ; 18)(\mathrm{q} 21 ; \mathrm{q} 21)$ in MALT lymphomas of different sites: significant association with CagA strains of Helicobacter pylori in gastric MALT lymphoma. Blood. 2003;102(3):1012-18.

13. Stolte M, Kroher G, Meining A, Morgner A, Bayerdorffer E, Bethke B. Comparison of Helicobacter pylori and $\mathrm{H}$ heilmannii gastritis matched control study involving 404 patients. Scand J Gastroenterol 1997;32:28-33.

14. O'Rourke JL, Dixon MF, Jack A, Enno A, Lee A. Gastric B-cell mucosa-associated lymphoid tissue (MALT) lymphoma in an animal model of 'Helicobacter heilmannii' infection. J Pathol. 2004; 203:896-903

15. Isaacson PG,Du MQ. MALT lymphoma: from morphology to molecules. Nature Reviews Cancer. 2004;4:644-653.

16. Ott G, Katzenberger T, Greiner A, Kalla J, Rosenwald A, Heinrich $\mathrm{U}$, et al. The $\mathrm{t}(11 ; 18)(\mathrm{q} 21 ; 21)$ chromosome translocation is a frequent and specific aberration in low-grade but not high-grade malignant non-Hodgkin's lynphomas of the mucosa-associated lymphoid tissue (MALT) type. Cancer Res. 1997; 57:3944-3948.

17. Rosenwald A, Ott G, Stilgenbauer S, Kalla J, Bredt M, Katzenberger $\mathrm{T}$, et al. Exclusive detection of $\mathrm{t}(11 ; 18)(\mathrm{q} 21 ; \mathrm{q} 21)$ in extranodal marginal zone B cell lymphomas (MZBL) of MALT type in contrast to other MZBL and extranodal large B cell lymphomas. Am J Pathol. 1999;155:1817-21.

18. Liu H, Ye H, Dogan A, et al. T(11;18) (q21;q21) is associated with more advanced MALT lymphoma that expresses nuclear bcl10. Blood. 2001;98:1182-7.

19. Remstein ED, James CD, Kurtin PJ. Incidence and subtype specificity of API2-MALT1 fusion translocations in extranodal, nodal, and splenic marginal zone lymphomas. Am J Pathol. 2000; 156:1183-8.

20. Liu H, Ye H, Ruskone-Fourmestraux A, De Jong D, Pileri S, Thiede $\mathrm{C}$, et al. $\mathrm{T}(11 ; 18)$ is a marker for all stage gastric MALT lymphomas that will not respond to HP eradication. Gastroenterology. 2002; 122:1286-94.

21. Chuang SS, Lee C, Hamoudi RA, Liu H, Lee PS, Ye H, et al. High frequency of $\mathrm{t}(11 ; 18)$ in gastric mucosa-associated lymphoid tissue lymphomas in Taiwan, including one patient with high-grade transformation. Br J Haematol. 2003; 120:97-100.

22. Baens M, Maes B, Steyls A, Geboes K, Marynen P, De WolfPeeters C. The product of the $\mathrm{t}(11,18)$, an API2-MLT fusion marks nearly half of gastric MALT type lymphomas without large cell proliferation. Am J Pathol. 2000:156(4):1433-9.

23. Zhang Q, Siebert R, Yan M, Hinzmann B, Cui X, Xue L et al. Inactivating mutations and overexpression of $\mathrm{Bcl10}$, a caspase recruitment domain-containing gene, in MALT lymphoma with $\mathrm{t}$ $(1 ; 14)(\mathrm{p} 22 ; \mathrm{q} 32)$. Nat Genet. 1999;22:63-68

24. Willis TG, Jadayel DM, Du MQ, Peng H, Perry AR, Abdul-Rauf $\mathrm{M}$, et al. Bcl-10 is involved in $\mathrm{t}(1 ; 14)(\mathrm{p} 22 ; \mathrm{q} 32)$ of MALT B cell lymphoma and mutated in multiple tumor types. Cell. 999;96:35-45.

25. Streubel B, Simonitsch-Klupp I, Mullauer L, Lamprecht A, Huber $\mathrm{D}$, Siebert R, et al. Variable frequencies of MALT lymphomaassociated genetic aberrations in MALT lymphomas of different sites. Leukemia. 2004;18:1722-6.

26. Du M, Peng H, Shing N, Isaacson PG, Pan L. The accumulation of p53 abnormalities is associated with progression of mucosaassociated lymphoid tissue lymphoma. Blood. 1995;86:4587-93.

27. Isaacson PG, Spencer J. Malignant lymphoma of mucosa-associated lymphoid tissue. Histopathology. 1987;11(5):445-62.

28. Chan JKC, Ng CS, Isaacson PG. Relationship between high-grade lymphoma and low-grade B-cell mucosa-associated lymphoid tissue lymphoma (MALToma) of the stomach. Am J Pathol. 1990;136: 1153-64.

29. Montalban C, Manzanal A, Castrillo JM, Escribano L, Bellas C. Low grade gastric B-cell MALT lymphoma progressing into high grade lymphoma. Clonal identity of the two stages of the tumor, unusual bone involvement and leukemic dissemination. Histopathology. 1995;27:89-91.

30. de Jong D, Boot H, van Heerde P, Hart GA, Taal BG. Histological grading in gastric lymphoma: pretreatment criteria and clinical relevance. Gastroenterology. 1997;112:1466-74.

31. Hussel T, Isaacson PG, Crabtrie JE, Spencer J. Helicobacter specific tumor-infiltrating $\mathrm{T}$ cells provide contact dependent help for the growth of malignant B cells in low grade gastric lymphoma of mucosa-associated lymphoid tissue. J Pathol. 1996;178:122-7.

32. Faria RE, Morais JC, Carneiro ACS, Rocha AFM, Silva SG, Madi K, El al. Linfomas MALT do estômago: estudo clinicopatológico de 30 pacientes submetidos à gastrectomia. J Brás Patol. 1998; 34286-295.

33. Cogliatti SB, Schmid U, Schumscher U, Eckert F, Hansmann ML, Hedderich J, et al. Primary B-cell gastric lymphoma: a clinicopathological study of 145 patients. Gastroenterology. 1991;101: 1159-70

34. Castrillo JM, Montalban C, Obeso G, Piris MA, Rivas MC. Gastric B-cell mucosa associated lymphoid tissue lymphoma: a clinicopathological study in 56 patients. Gut. 1992;33:1307-11

35. Taal BG, Boot H, van Heerde P, de Jong D, Hart AA, Burgers JM. Primary non-Hodgkin lymphoma of the stomach: endoscopic pattern and prognosis in low versus high grade malignancy in relation to the MALT concept. Gut. 1996; 39(4): 556-61

36. Koch P, del Valle F, Berdel WE, Willich NA, Reers B, Hiddemann W, et al. Primary gastrointestinal non-Hodgkin's lymphoma: I. Anatomic and histologic distribution, clinical features, and survival data of 371 patients registered in the German Multicenter Study GIT NHL 01/92. J Clin Oncol. 2001;19:3861-73.

37. Thieblemont C, Berger F, Dumontet C, Moullet I, Bouafia F, Felman $\mathrm{P}$, et al. Mucosa-associated lymphoid tissue lymphoma is a disseminated disease in one third of 158 patients analyzed. Blood. 2000;95:802-6

38. Du MQ, Xu CF, Diss TC, Peng HZ, Wotherspoon AC, Isaacson PG, et al. Intestinal dissemination of gastric MALT lymphoma. Blood. 1996;88:4445-51. 
39. Du MQ, Peng HZ, Dogan A, Diss TC, Liu H, Pan LX, et al. Preferential dissemination of B-cell gastric mucosa-associated lymphoid tissue (MALT) lymphoma to the splenic marginal zone. Blood. 1997;90:4071-77.

40. Tzankov A, Hittmair A, Hermelink HKM, Rüdiger T, Dirnhofer S. Primary gastric follicular lymphoma with parafollicular monocytoid B-cells and lymphoepithelial lesions, mimicking extranodal marginal zone lymphoma of MALT. Virchows Arc. 2002;441:614-17.

41. Wündisch T, Neubauer A, Stolte M, Ritter M, Thiede C. B-cell monoclonality is associated with lymphoid follicles in gastritis. Am J Surg Pathol. 2003;27:882-7.

42. Thiede C, Wündisch T, Alpen B, Neubauer B, Morgner A, Schmitz $\mathrm{M}$, et al. Long-term persistence of monoclonal B cells after cure of Helicobacter pylori infection and complete histologic remission in gastric mucosa-associated lymphoid tissue B-cell lymphoma. J Clin Oncol. 2001;19:1600-9.

43. Bayerdorffer E, Neubauer A, Rudolph B, Thiede C, Lehn N, Eidt S, et al. Regression of primary gastric lymphoma of mucosa-associated lymphoid tissue type after cure of Helicobacter pylori infection: MALT Lymphoma Study Group. Lancet. 1995;345:1591-94.

44. Steinbach G, Ford R, Glober G, Sample D, Hagemeister FB, Lynch $\mathrm{PM}$ et al. Antibiotic treatment of gastric lymphoma of mucosaassociated lymphoid tissue: an uncontrolled trial. Ann Intern Med. 1999; 131:88-95.

45. Fischbach W, Goebeler-Kolve ME, Dragosics B, Greiner A, Stolte M. Long term outcome of patients with gastric marginal zone B cell lymphoma of mucosa associated lymphoid tissue (MALT) following exclusive Helicobacter pylori eradication therapy: experience from a large prospective series. Gut. 2004;53:34-37.

46. de Jong D, Aleman BM, Taal BG, Boot H. Controversies and consensus in the diagnosis, work-up and treatment of gastric lymphoma: an international survey. Ann Oncol. 1999;10:275-80.

47. El-Zimaity HM, Wotherspoon A, de Jong D; Houston MALT lymphoma Workshop. Interobserver variation in the histopathological assessment of malt/malt lymphoma: towards a consensus. Blood Cells Mol Dis. 2005;34:6-6.

48. Nakamura S, Matsumoto T, Suekane H, Takeshita M, Hizawa K, Kawasaki M, et al. Predictive value of endoscopic ultrasonografy for regression of gastric low grade and high grade MALT lymphomas after eradication of Helicobacter pylori. Gut. 2001; 48: 454-60.

49. Morgner A, Miehlke S, Fischbach W, Schmitt W, Müller-Hermelink $\mathrm{H}$,Greiner $\mathrm{A}$, et al. Complete remission of primary high-grade Bcell gastric lymphoma after cure of Helicobacter pylori infection. J Clin Oncol. 2001;19:2041-8.

50. Alsolaiman MM, Bakis G, Nazeer T, MacDermott RP, Balint JA. Five years of complete remission of gastric diffuse large B cell lymphoma after eradication of Helicobacter pylori infection. Gut 2003;52:507-09.

51. Ruskone-Fourmestraux A, Lavergne A, Aergerter PH, Megraud F, Palazzo L, de Mascarel A, et al. Predictive factors for regression of gastric MALT lymphoma after anti-Helicobacter pylori treatment. Gut. 2001;48:297-303.

52. Jones SE, Miller T, Connors JM. Long-term follow-up and analysis for prognostic factors for patients with limited-stage diffuse largecell lymphoma treated with initial chemotherapy with or without adjuvant radiotherapy. J Clin Oncol 1989;7(9):1186-91.

53. Fisher RI, Gaynor ER, Dahlberg S, Oken MM, Grogan TM, Mize EM, et al. Comparison of a standard regimen (CHOP) with three intensive chemotherapy regimens for advanced non-Hodgkin's lymphoma. N Engl J Med. 1993;328(14):1002-6.

54. Hallack Neto AE, Pereira J, Dorlhiac-Llacer P, Beitler B, Chamone DAF, Llacer PD, et al. Results of CHOP chemotherapy for diffuse large B-cell lymphoma. Braz J Med Biol Res. 2006;39(10):131522.

55. Coiffier B, Lepage E, Briere J, Herbrecht R, Tilly H, Bouabdallah $\mathrm{R}$, et al. Chop chemotherapy plus rituximab compared with CHOP alone in elderly patients with diffuse large-B-cell lymphoma. N Engl J Med. 2002;346(4):235-42.

56. Levy M, Copie-Bergman C, Traulle C, Lavergne-Slove A, Brousse $\mathrm{N}$, Flejou JF, et al. Groupe d'Etude des lymphomes de l'Adulte (GELA). Conservative treatment of primary gastric low-grade B-cell lymphoma of mucosa-associated lymphoid tissue: predictive factors of response and outcome. Am J Gastroenterol. 2002;97(2):292-7.

57. Jäger G, Neumeister P, Brezinschek R, Hinterleitner T, Fiebiger W, Penz M, et al. Treatment of extranodal marginal zone B-cell lymphoma of mucosa-associated lymphoid tissue type with cladribine: a phase II study. J Clin Oncol. 2002;20(18):3872-7.

58. Conconi A, Martinelli G, Thiéblemont C, Ferreri AJ, Devizzi L, Peccatori $\mathrm{F}$, et al. Clinical activity of rituximab in extranodal marginal zone B-cell lymphoma of MALT type. Blood. 2003; 102(8):2741-5.

59. Koch P, del Valle F, Berdel WE, Willich NA, Reers B, Hiddemann $\mathrm{W}$, et al. Primary gastrointestinal non-Hodgkin's lymphoma: II. Combined surgical and conservative management only in localized gastric lymphoma - Results of the Prospective German Multicenter Study GIT NHL 01/92. J Clin Oncol. 2001;19(18):3874-83.

60. Schechter NR, Portlock CS, Yahalom J. Treatment of mucosaassociated lymphoid tissue lymphoma of the stomach with radiation alone. J Clin Oncol. 1998;16(5):1916-21.

61. Costa RO. Linfoma não Hodgkin extralinfonodal gástrico: estudo retrospectivo do Serviço de Hematologia do Hospital das Clínicas da Faculdade de Medicina da Universidade de São Paulo [Dissertação]. São Paulo: Faculdade de Medicina, Universidade de São Pau1.. 2007

Avaliação: Editor e dois revisores externos

Conflito de interesse: sem conflito de interesse

Recebido:23/03/2009

Aceito após modificações: 12/07/2009 